\title{
Characterization of a Maize Wip1 Promoter in Transgenic Plants
}

\author{
Shengxue Zhang ${ }^{1, \dagger}$, Yun Lian ${ }^{2, \dagger}$, Yan Liu ${ }^{1}$, Xiaoqing Wang ${ }^{1}$, Yunjun Liu ${ }^{1, *}$ \\ and Guoying Wang ${ }^{1, *}$
}

1 Institute of Crop Sciences, Chinese Academy of Agricultural Sciences, Zhongguancun South Street 12, Beijing 100081, China; E-Mails: xueshzhang@163.com (S.Z.); lyer09@163.com (Y.L.); xiaoqingshiyan@126.com (X.W.)

2 Institute of Industrial Crops, Henan Academy of Agricultural Sciences, Zhengzhou 450002, Henan, China; E-Mail: lianyun262@126.com

$\dagger$ These authors contributed equally to this work.

* Authors to whom correspondence should be addressed; E-Mails: yunjunliu@gmail.com (Y.L.); gywang604@gmail.com (G.W.); Tel.: +86-10-8210-5863 (Y.L.); +86-10-8210-5862 (G.W.).

Received: 2 October 2013; in revised form: 22 November 2013 / Accepted: 25 November 2013 / Published: 6 December 2013

\begin{abstract}
The Maize Wipl gene encodes a wound-induced Bowman-Birk inhibitor (BBI) protein which is a type of serine protease inhibitor, and its expression is induced by wounding or infection, conferring resistance against pathogens and pests. In this study, the maize Wipl promoter was isolated and its function was analyzed. Different truncated Wipl promoters were fused upstream of the GUS reporter gene and transformed into Arabidopsis, tobacco and rice plants. We found that (1) several truncated maize Wipl promoters led to strong GUS activities in both transgenic Arabidopsis and tobacco leaves, whereas low GUS activity was detected in transgenic rice leaves; (2) the Wip1 promoter was not wound-induced in transgenic tobacco leaves, but was induced by wounding in transgenic rice leaves; (3) the truncated Wipl promoter had different activity in different organs of transgenic tobacco plants; (4) the transgenic plant leaves containing different truncated Wipl promoters had low GUS transcripts, even though high GUS protein level and GUS activities were observed; (5) there was one transcription start site of Wipl gene in maize and two transcription start sites of GUS in Wip1::GUS transgenic lines; (6) the adjacent $35 \mathrm{~S}$ promoter which is present in the transformation vectors enhanced the activity of the truncated Wipl promoters in transgenic tobacco leaves, but did not influence the
\end{abstract}


disability of truncated Wip $_{1231}$ promoter to respond to wounding signals. We speculate that an ACAAAA hexamer, several CAA trimers and several elements similar to ACAATTAC octamer in the 5'-untranslated region might contribute to the strong GUS activity in Wip $_{1231}$ transgenic lines, meanwhile, compared to the 5'-untranslated region from Wip P $_{1231}$ transgenic lines, the additional upstream open reading frames (uORFs) in the 5'-untranslated region from $W_{i p} 1737$ transgenic lines might contribute to the lower level of GUS transcript and GUS activity.

Keywords: Wip 1; promoter; transcriptional start site; transgenic plant

\section{Introduction}

It is necessary to use different promoters when multiple genes are cloned in tandem in transgenic plants because multiple copies of a single promoter could lead to the silencing of the transgenes. Promoters may be classified as constitutive, tissue-specific, or inducible based on their expression patterns. The most widely used constitutive promoters include the CaMV 35S promoter [1], the maize ubiquitin promoter [2], and the rice actin promoter [3]. Several other strong promoters have also been isolated and identified from plants or viruses [4-6]. Although many promoters have been isolated and tested, only a few have been successfully used in agricultural biotechnology. The constitutive expression of certain genes might be harmful to their host plants, affecting plant growth and development; inducible or tissue-specific promoters would be more useful than constitutive promoters in these cases.

The function of a promoter is normally determined by the combinatorial action of multiple regulatory elements, i.e., enhancers and cis-elements, and by the interactions between regulatory elements and nuclear protein factors [7]. For the CaMV $35 \mathrm{~S}$ promoter, the region from -46 to +1 upstream of the gene is the basal promoter and the region from -343 to -46 acts as an enhancer [1]. Although the CaMV 35S promoter is presumed to be constitutive, some reports have shown that it is developmentally regulated [8] and can be affected by abiotic stress [9]. Negative cis-regulatory regions determine the tissue-specific activity of a number of promoters [10]. Besides the cis elements in DNA sequence affect transcription, various cis elements in mRNA have the functions to control the translation efficiency. Many reports have shown that the 5'-untranslated region (5'-UTR) and 3'-untranslated region (3'-UTR) can increase the translation efficiency [11]. Upstream open reading frames (uORFs) that are located in the 5'-UTR have been reported to generally downregulate the expression of the major open reading frame (mORF) through ribosomal stalling or reducing initiation efficiency [12]. However, a few uORFs can upregulate the expression of mORF [13]. Additionally, more and more reports showed that the $35 \mathrm{~S}$ promoter interferes with the tissue specificity, strength [14] or inducibility (our data, unpublished) of its adjacent promoter. The onset and extent of influence depends on the responsive nature of the adjacent promoter and the distance between the $35 \mathrm{~S}$ promoter and adjacent promoter [15].

The Bowman-Birk inhibitor (BBI) is a type of serine protease inhibitor, and its expression is induced by wounding or infection, conferring resistance against pathogens and pests [16]. It was 
reported that the BBI confers heavy metal and multiple drug tolerance in yeast [17]. There are seven BBI genes in rice and overexpression of the rice BBI2-3 conferred fungal pathogen resistance in transgenic rice plants [18]. The maize Wipl gene, encoding a wound-induced BBI protein, has been cloned, and the promoter of the gene might respond to wound signals [19,20]. In contrast to most BBIs, which inhibit trypsin and chymotrypsin proteases, both of the inhibitory domains of maize Wipl inhibit chymotrypsin [20]; however, these two domains have different evolutionary histories and ecological functions [21].

Here, we isolated the maize Wipl promoter and characterized its function in transgenic plants, showing that Wipl promoters showed different properties in dicot and monocot plants, and some truncated promoters under the influence of adjacent $35 \mathrm{~S}$ promoter can drive high GUS activities even with a low GUS transcriptional level.

\section{Results}

\subsection{Isolation and Analysis of the Maize Wip1 Promoter}

To isolate the maize Wipl promoter, we performed a BLAST analysis with the mRNA sequence of maize Wipl (X71396) in www.maizegdb.org [22]. The maize Wipl sequence was homologous to the genome sequence from $12,274,189$ to $12,273,525$ on chromosome 8 , and one intron was found in the Wipl coding region. Based on the maize genomic sequence, a 1737 bp fragment (chr8: 12,275,876-12,274,140) upstream of the translation start site of Wipl was amplified by PCR. The cis-elements in the promoter sequence were analyzed using the PlantCARE [23] and PLACE [24] databases, and the transcription start sites were predicated on the website: http://www.fruitfly.org/seq_tools/promoter.html [25]. Two putative TATA boxes and two corresponding potential transcription start sites were present in the promoter sequence. Six W-boxes and three GCC-boxes were found in the Wipl promoter. In addition, several CAAT-boxes, which are common cis-acting elements in promoter and enhancer regions, were also found (Figure 1).

\subsection{Truncated Wip1 Promoter Has Strong Activity in Transgenic Arabidopsis and Tobacco Leaves}

To analyze the function of the Wipl promoter, several expression vectors $\left(\mathrm{pWip}_{1737}, \mathrm{pWip}_{1500}\right.$, $\mathrm{pWip}_{1231}, \mathrm{pWip}_{1191}, \mathrm{pWip}_{791}, \mathrm{pWip}_{491}$ ) were constructed (Figure 2A, Tables 1 and 2). The constructed plasmids were transformed into tobacco, and at least ten independent transgenic tobacco lines for each construct were obtained. The transformations were confirmed by PCR analysis of genomic DNA using primers specific for GUS (data not shown). We performed quantitative analysis of GUS activity using leaf samples from 40 -day-old $\mathrm{T}_{3}$ progeny of plants. The results showed that the Wip $_{1231}$ promoter had strong activity, while no or weak activity was detected for the other truncated promoters (Figure 2B). To confirm the results of the GUS activity analysis, the seedlings were subjected to histochemical staining. Strong GUS staining was observed for the seedlings that were transgenic for the Wip pr31 $_{12}$ promoter and $35 \mathrm{~S}$ promoter, whereas no or light staining was observed for the seedlings that were transgenic for the full-length and other truncated promoters (Figure 3), consistent with the GUS activity analysis results. To investigate whether the truncated Wip $_{1231}$ promoter also had strong activity in other plant species, the constructs were transformed into Arabidopsis. As expected, the Wip ${ }_{1231}$ 
promoter also drove high GUS activity in transgenic Arabidopsis plant leaves (Figure 2C), further confirming the high activity of the truncated Wip ${ }_{1231}$ promoter.

Figure 1. The maize Wipl promoter sequence. The start codon (ATG) and putative transcription start sites are indicated in larger letters. The putative TATA boxes are shadowed and italicized. The W-box and GC-box are shadowed only. The primers used for PCR amplification are underlined and given corresponding names. Triangle $(\boldsymbol{\Delta})$ indicates the transcription start site of GUS in Wip $p_{1231}: \because G U S$ line; rhombuses ( $\left.\downarrow\right)$ indicate the transcription start site of GUS in Wip $_{1737}: \because G U S$ line; asterisk ( $\star$ ) means the transcription start site of Wipl in maize.

1

61

121

181

241

301

361

421

481

541

601

661

721

781

841

901

961

1021

1081

1141

1201

1261

1321

1381

1441

1501

1561

1621

1681
GGCTCCGTTC TACTTGACTC CTCAACCAAA CACTACCTTA CATAGTGGTT GGTATAGGGT AGTCATTTGG CGGTAAAGTC AAACTTTTTT AGCTTCTATT TTATCACACT ATGCCTATGG TAAAGTCAAA CTTCCCCTAG CCGAGCTGCG GGCGTCCATT TGTATCTCAT CGCCCAAACT CGCTTCTTGC AGCCAACCAA ACGTACTATA ACTGCATATG GTAGGCATGT CTGGCGTAAA GACATATTTG TTTTGGATTA TAATCTCTTC AGATTATATA ATCTAGCGTA AATAATTCAG CAGATAAACA AACATCTAGA TTATGAGTCC AGATTATATA TATAATCTAA AGCACAGATT ATGATAATCT CATAATCTCC TCAAGAGTAA CTTATTGGA ATTATTTTTA GCAAAAGACC AACTACCCAT GGTTATGTAA ATAGAAATA TAGTATATTA CATTCTTCTT TCCTCACCTA ATACACAATC AGATTCTCCA CTGTGCCTCT CGCTGTCAAT CTCTTTTACC ACCGCTAGCC GTTCATCGCG TCGCCGTCTC TTACTGTTTC TAGTGATAGA ATGTCATAAT TGTACCAAAT ATCAATTAAA CAAACAAGGA TTGTCTTACG AATAATCTAT ATTTGTATAA TCTAGGCTAC CGCAAACAGA TACATGTAGA TTATAATCTA TCCAGATTAT AATTTGGACT ATATAATCTA TATTATAACC TAGATTGTAT AATCTATAAG CTGAAAACAT CCAACCAGTC ACACCCTAAC TACACTTAAG TGAACCCTAC TAATCATTTT TTACTAAAAT GATGATTTTT TGTCACAGGT AAAAAAAGAT ACTCCGTCAT TTTTCCTTTT TTAGAAAAAA GAGGGGGAC AGATTGAAGA AACTACCAGA TATATAAATT GAGAAAGTAA AAGTTACTCC CTCCGTTTCT TTTTAGTTGT CGCTGGATAA TTTAATTTTG CACTATCCAG TGACAACTAA AACGAAACGg AGGGAGTAGA TCATAATGGG GCAATTACAC CCAACAATAA TAAAGTTACA CGACAACATG GCAATTCAAG TACTACTACT AAGTACTAAC AATAGAAAAT GAAAAAAAAA ACTGTTTATT GGTGGTTGTT TCAGGGAAAG CTAATAACTA AGAGTTAAGg ACACGCCACT CTTCACAAGT CGGTTGTTTT AAATATGTCC AACAATATAC AAgGCACTGC CTGATTAGAT CGAGAGGGGA AGATTATTAC TATACACTGT ACATCACACT ATATTCCATT GTTTTACCTC ATTGTGAATC GCACGCATGA AATGGTGAAT AAGGCTAGGA TCAATCAACC GATGCTTCTA CCAGCTGCGC GTCAAGCCAC AAAACTGTGC TGATCGGATA ACACGTCGTC GTCACTTCCG TCCATTTTGG ACCAAATACA TACGCTGATG AGGATGATCG GAAATGATCA CGAGGAAGAG ATGGTTCGTT ATGCCATACG ACTCGCCGCC ATGAGTCAAA GTTCCGCCTA ACAAAATGTA TGAGCTGGAA GCGTCTATCC ATCCATCGCC CCCCAAAGAA ATGCCATTGC AGGAGGACTA CACGGCGGCA GGCAATGCCA TGCATGTTCA GATCTCGGCG CCGCC TATAA GTAGCTTCCT CCAGTGCACT GCTGTTGGCG CAACGAAGCT TGCTTCTACG AGAGGATATA GAGAGGAAGA ACAGCTCGTC CGAGACCÂTG R1231c 
Figure 2. The Wipl promoters and their activities in transgenic tobacco and Arabidopsis plant leaves. (A) Schematics of the full-length and truncated Wipl promoters. The numbers and/or letters in front of each schematic represent the names of the corresponding constructs; (B) The GUS activities of 40-day-old transgenic tobacco plants containing different constructs. Error bars represent the S.E. of $n$ independent transgenic lines, $n=9$ for 1737 and $1500 ; n=16$ for 1231 and $35 \mathrm{~S} ; n=3$ for $1191,791,491$ and WT; and (C) The GUS activity of 20-day-old transgenic Arabidopsis plants. Error bars represent the S.E. of $n$ independent transgenic lines, $n=6$ for 1737 and 1500; $n=20$ for 1231 and $35 \mathrm{~S} ; n=3$ for WT. ND indicates not determined.

A

1741

1500

1231

1191

791

491

$35 \mathrm{~S}$

WT

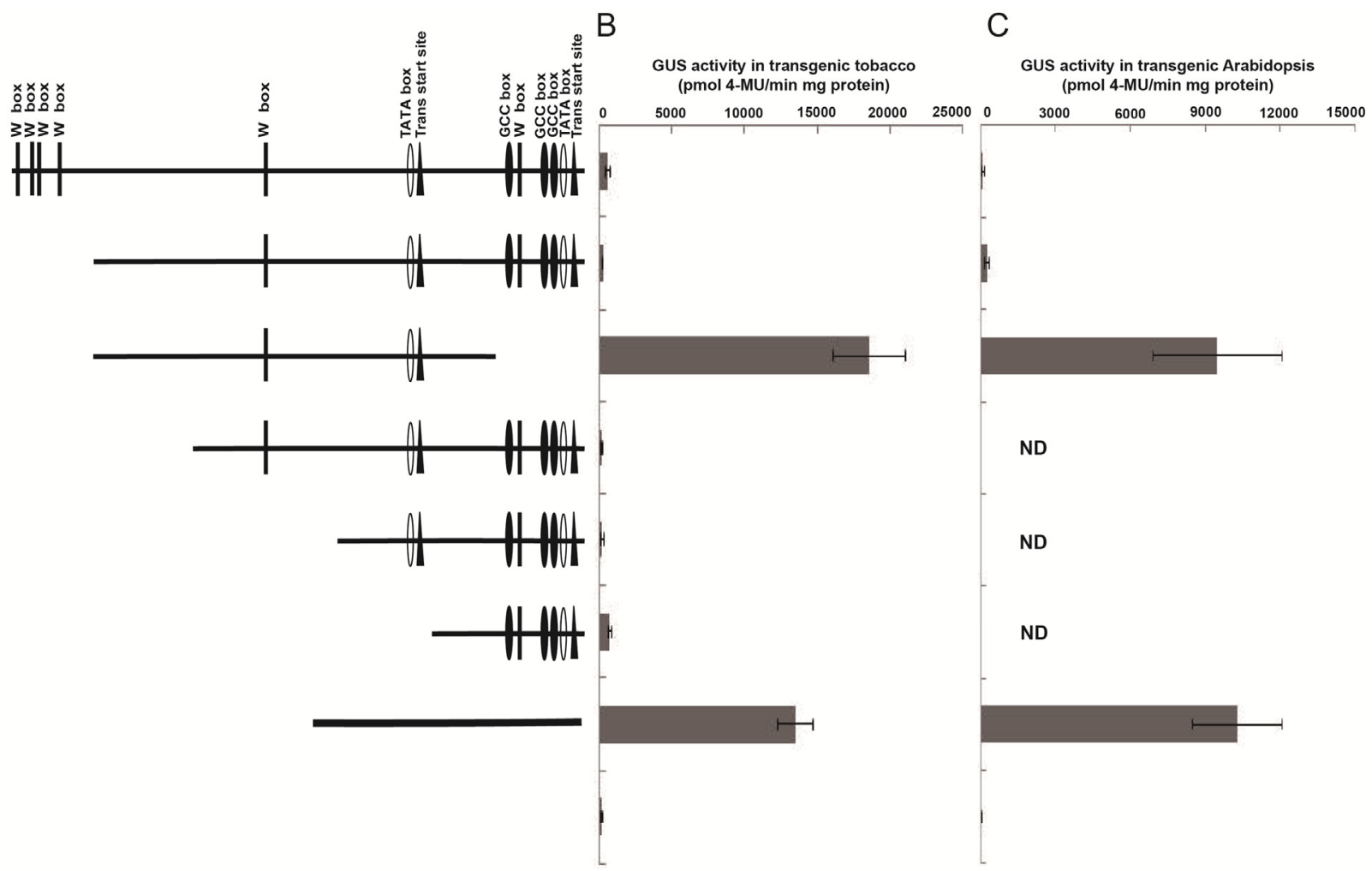

Table 1. The sequence of the primers used in the paper.

\begin{tabular}{|c|c|}
\hline Primers & Sequence \\
\hline F1737 & 5'-AACTGCAGGGCTCCGTTCTACTTGACT-3' \\
\hline $\mathrm{R} 1737$ & 5'-CGGGATCCGGTCTCGGACGAGCTGTTCTT-3' \\
\hline F1231 & 5'-AACTGCAGTTTGTTTTGGATTATAAT-3' \\
\hline F1191 & 5'-AACTGCAGCGCGTCGCCGTCTCTTACTGT-3' \\
\hline F791 & 5'-AACTGCAGTTCTTTTTAGTTGTCGCTGGA-3' \\
\hline F491 & 5'-AACTGCAGGGGAAGATTATTACTATACAC-3' \\
\hline $\mathrm{R} 1231$ & 5'-CGGGATCCTTCCTCGTGATCATTTCCG-3' \\
\hline F1231A & 5'-AACTGCAGCCTTACATAGTGGTTGGT-3' \\
\hline F1231B & 5'-AACTGCAGGCTTCTATTTTATCACAC-3' \\
\hline F1231C & 5'-AACTGCAGGGCGTCCATTTGTATCTC-3' \\
\hline R1231a & 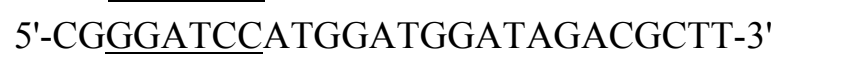 \\
\hline $\mathrm{R} 1231 \mathrm{~b}$ & 5'-CGGGATCCGCCGAGATCTGAACATGC-3' \\
\hline $\mathrm{R} 1231 \mathrm{c}$ & 5'-CGGGATCCCCTCTCGTAGAAGCAAGC-3' \\
\hline
\end{tabular}


Table 2. The primers used to amplify different truncated promoters.

\begin{tabular}{ccc}
\hline The amplified fragment & Forward Primer & Reverse Primer \\
\hline Wip $_{1500}$ & $\mathrm{~F} 1231$ & $\mathrm{R} 1737$ \\
Wip $_{1231}$ & $\mathrm{~F} 1231$ & $\mathrm{R} 1231$ \\
Wip $_{1191}$ & $\mathrm{~F} 1191$ & $\mathrm{R} 1737$ \\
Wip $_{791}$ & $\mathrm{~F} 791$ & $\mathrm{R} 1737$ \\
Wip $_{491}$ & $\mathrm{~F} 491$ & $\mathrm{R} 1737$ \\
Wip $_{1231 \mathrm{~A}}$ & $\mathrm{~F} 1231 \mathrm{~A}$ & $\mathrm{R} 1231$ \\
Wip $_{931}$ & $\mathrm{~F} 1191$ & $\mathrm{R} 1231$ \\
Wip $_{1231 \mathrm{C}}$ & $\mathrm{F} 1231 \mathrm{C}$ & $\mathrm{R} 1231$ \\
Wip $_{1231 \mathrm{a}}$ & $\mathrm{F} 1231$ & $\mathrm{R} 1231 \mathrm{a}$ \\
Wip $_{1231 \mathrm{~b}}$ & $\mathrm{~F} 1231$ & $\mathrm{R} 1231 \mathrm{~b}$ \\
Wip $_{1231 \mathrm{c}}$ & $\mathrm{F} 1231$ & $\mathrm{R} 1231 \mathrm{c}$ \\
Wip $_{1231 \mathrm{Aa}}$ & $\mathrm{F} 1231 \mathrm{~A}$ & $\mathrm{R} 1231 \mathrm{a}$ \\
Wi $_{1231 \mathrm{Ab}}$ & $\mathrm{F} 1231 \mathrm{~A}$ & $\mathrm{R} 1231 \mathrm{~b}$ \\
Wip $_{1231 \mathrm{Ac}}$ & $\mathrm{F} 1231 \mathrm{~A}$ & $\mathrm{R} 1231 \mathrm{c}$ \\
Wip $_{1231 \mathrm{Ba}}$ & $\mathrm{F} 1231 \mathrm{~B}$ & $\mathrm{R} 1231 \mathrm{a}$ \\
Wip $_{1231 \mathrm{Bb}}$ & $\mathrm{F} 1231 \mathrm{~B}$ & $\mathrm{R} 1231 \mathrm{~b}$ \\
Wip $_{1231 \mathrm{Bc}}$ & $\mathrm{F} 1231 \mathrm{~B}$ & $\mathrm{R} 1231 \mathrm{c}$ \\
Wip $_{1231 \mathrm{Ca}}$ & $\mathrm{F} 1231 \mathrm{C}$ & $\mathrm{R} 1231 \mathrm{a}$ \\
Wip $_{1231 \mathrm{Cb}}$ & $\mathrm{F} 1231 \mathrm{C}$ & $\mathrm{R} 1231 \mathrm{~b}$ \\
Wip $_{1231 \mathrm{Cc}}$ & $\mathrm{F} 1231 \mathrm{C}$ & $\mathrm{R} 1231 \mathrm{c}$ \\
\hline
\end{tabular}

Figure 3. Histochemical GUS staining of 14-day-old transgenic tobacco plants. $\mathrm{T}_{2}$ transgenic tobacco seeds were germinated on MS medium plates with $30 \mathrm{mg} / \mathrm{L}$ Hygromycin B to eliminate the non-transgenic plants. The surviving 14-day-old seedlings were immersed in GUS staining solution and incubated overnight at $37{ }^{\circ} \mathrm{C}$. Then, the samples were de-pigmented with $70 \%$ ethanol at $37{ }^{\circ} \mathrm{C}$ until the chlorophyll had completely disappeared.

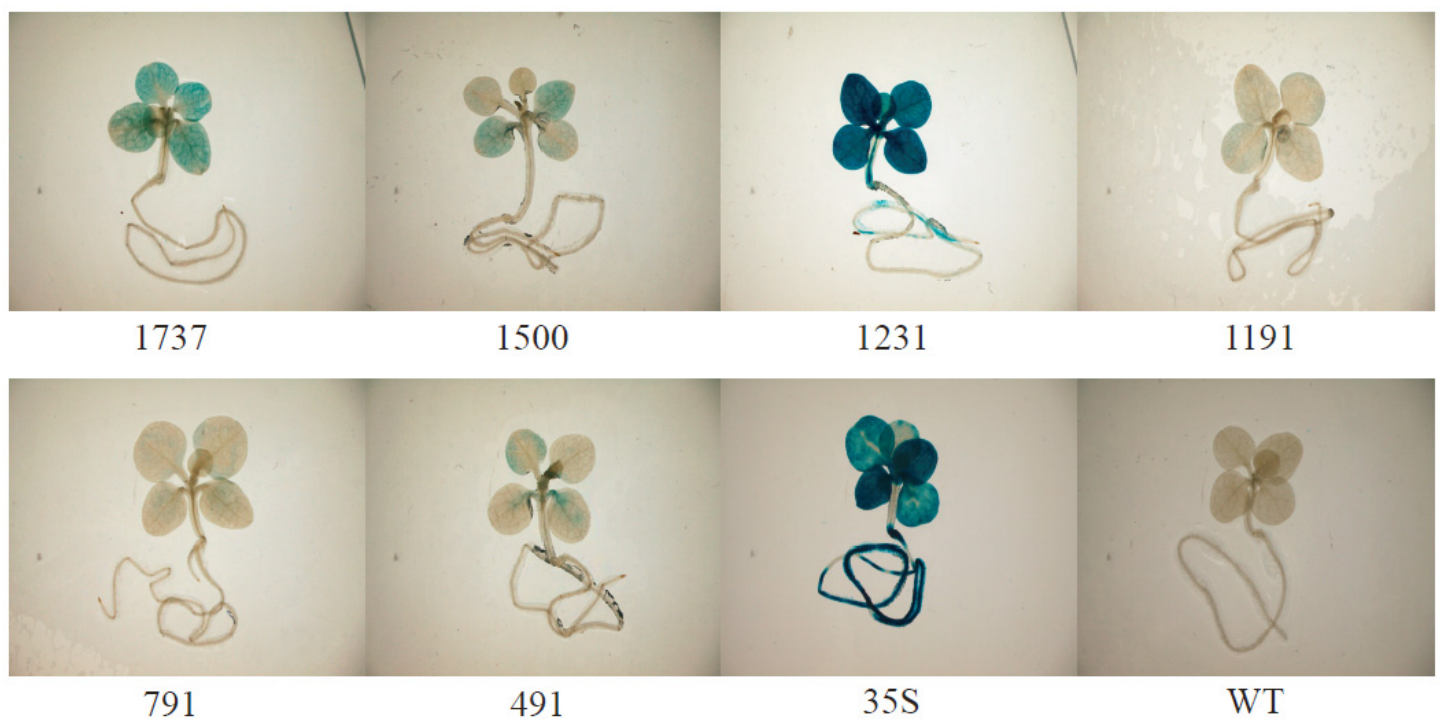


To find out the potential negative cis-acting elements, detailed $5^{\prime}$ and $3^{\prime}$ deletions of Wip $_{1737}$, based on Wip $_{1231}$, were performed, involving the generation of an additional 15 deletion constructs (pWip $_{1231 \mathrm{~A}}, \mathrm{pWip}_{1231 \mathrm{C}}, \mathrm{pWip}_{931}, \mathrm{pWip}_{1231 \mathrm{a}}, \mathrm{pWip}_{1231 \mathrm{~b}}, \mathrm{pWip}_{1231 \mathrm{c}}, \mathrm{pWip}_{1231 \mathrm{Aa}}, \mathrm{pWip}_{1231 \mathrm{Ab}}, \mathrm{pWip}_{1231 \mathrm{Ac}}$, pWip ${ }_{1231 \mathrm{Ba}}, \mathrm{pWip}_{1231 \mathrm{Bb}}, \mathrm{pWip}$ 1231Bc $_{1}, \mathrm{pWip}_{1231 \mathrm{Ca}}, \mathrm{pWip}_{1231 \mathrm{Cb}}, \mathrm{pWip}_{1231 \mathrm{Cc}}$; Figure 4A, Tables 1 and 2). These constructs were transformed into Arabidopsis, and the GUS activity in the transgenic plant leaves was analyzed. The results showed that $W_{i 231}$, Wip $p_{1231 \mathrm{C}}$, and $W_{i p_{931}}$, which were of the same $3^{\prime}$ end as Wip $_{1231}$, had high activity similar to that of Wip $_{1231}$, while the other Wipl promoter fragments presented very low levels of activity (Figure 4C). To further confirm the functions of these three fragments, three constructs ( $\mathrm{pWip}_{1231 \mathrm{~A}}, \mathrm{pWip}_{1231 \mathrm{C}}$ and $\mathrm{pWip}_{931}$ ) were also transformed into tobacco, respectively. High GUS activities were observed in the transgenic tobacco leaves transformed with each of these three promoters (Figure 4B).

Figure 4. The finely truncated Wipl promoters and their activity in transgenic Arabidopsis and tobacco plant leaves. (A) Schematics of the finely truncated Wipl promoters. The numbers or/and letters in front of each schematic indicate the names of the corresponding constructs; (B) The GUS activities of transgenic tobacco plants. Error bars represent the S.E of $n$ independent transgenic lines, $n=8$ for 1737,1231 and $35 \mathrm{~S} ; n=18$ for $1231 \mathrm{~A}$, $1231 \mathrm{C}$ and 931; $n=3$ for WT. ND indicates not determined; and (C) The GUS activities of transgenic Arabidopsis plants containing different constructs. Error bars represent the S.E. of $n$ independent transgenic lines, $n=3$ for WT, and $n=6$ for the others.

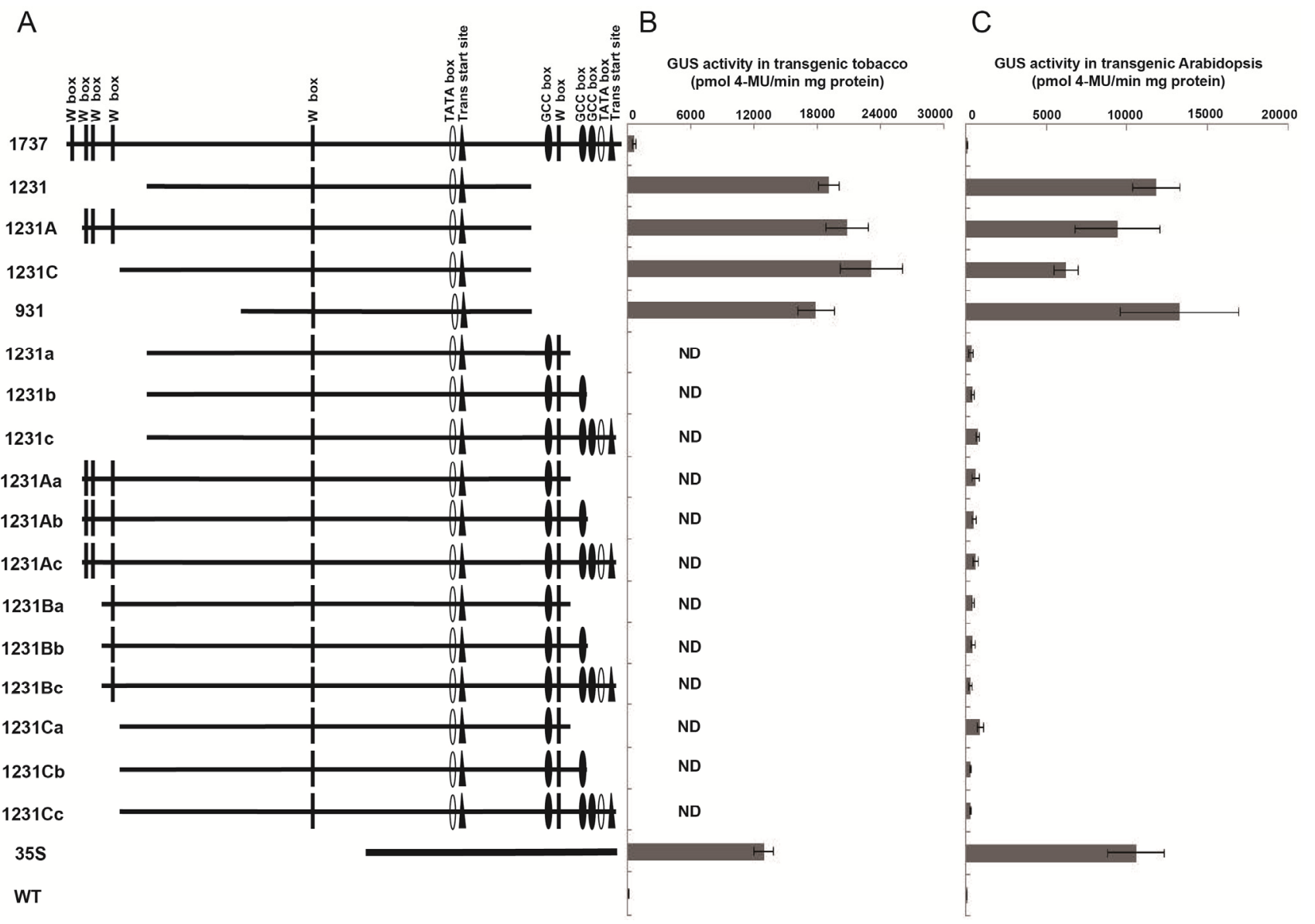


2.3. Wip1 Promoters Are not Induced by Wounding and Have Different Activity in Different Organs in Transgenic Tobacco

It has been shown that the expression of Wipl gene is wound-induced in maize $[19,20]$. We investigated whether the Wipl promoter is wound-induced in transgenic tobacco plant leaves that were wounded with three different kinds of wounding methods, respectively. Under three different treatment conditions, to our surprise, wounding did not induce the increase of the activity of Wipl promoters (Figure 5), indicating that Wipl promoters are not wound-induced in transgenic tobacco.

Figure 5. GUS activity in transgenic tobacco leaves treated with wounding. The second leaves from apex of 40-day-old $\mathrm{T}_{3}$ tobacco plants grown in greenhouse were wounded using three different kinds of methods. GUS activities were assessed $24 \mathrm{~h}$ after wounding. A-NW and A-W mean non-wounded or wounded samples using the method described in Walker-Simmons, et al. [26]. B-NW and B-W mean non-wounded or wounded samples using the method described in An, et al. [27]. C-NW and C-W mean non-wounded or wounded samples using the method described in $\mathrm{Xu}$, et al. [28]. Data was shown as average \pm S.E. of 6 independent transgenic lines.

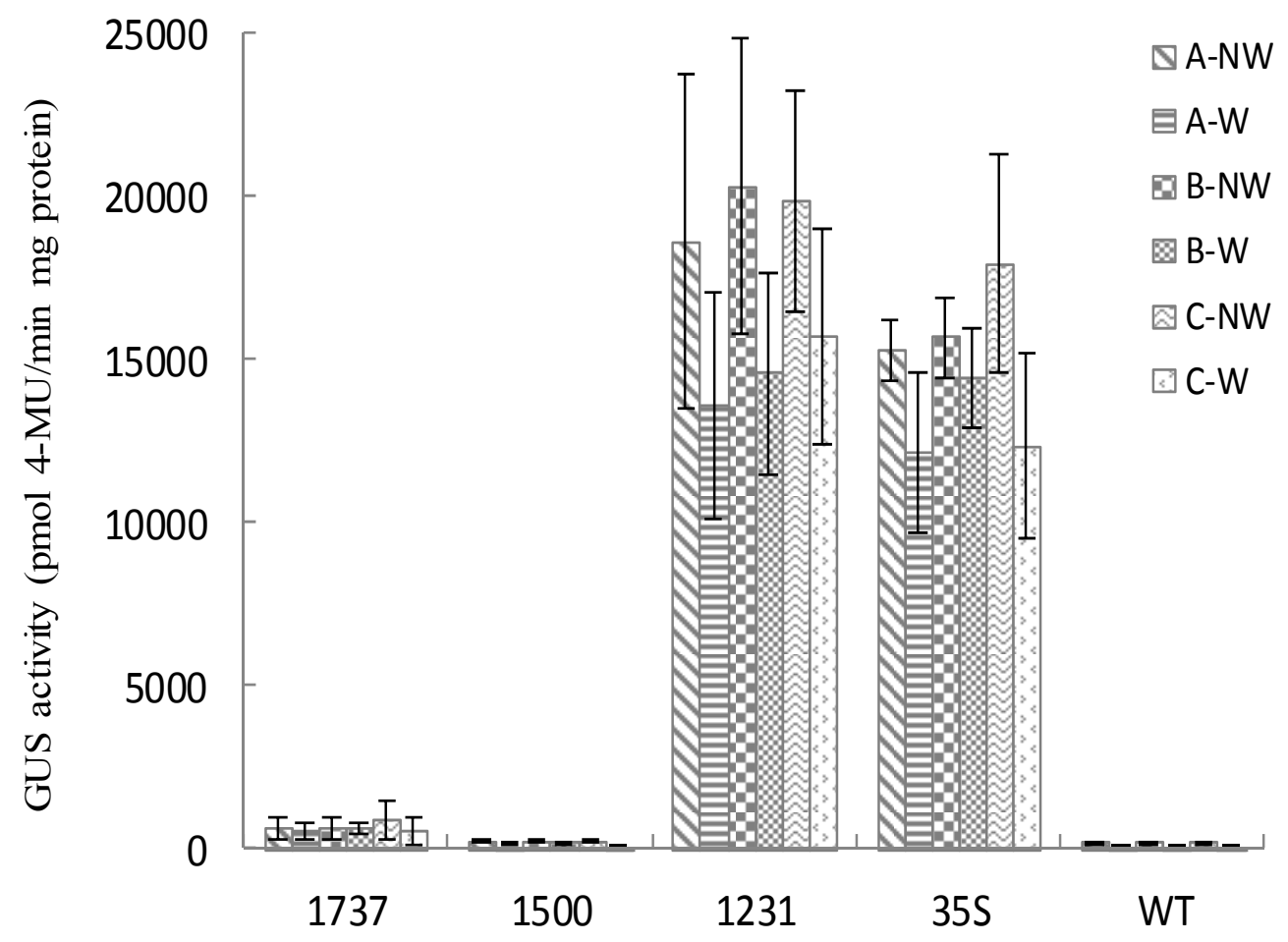

The GUS activities in different organs of the transgenic tobacco lines transformed with different truncated Wipl promoters or the control 35S promoter were analyzed. The results showed that the Wip $_{1231}$ promoter has high activity in the leaf and stem but low activity in the root and seed (Figure 6). 
Figure 6. GUS activity of different tissues of transgenic tobacco plants. Data was shown as average \pm S.E. of $n$ independent transgenic lines, $n=3$ for 1737,1500 and WT; $n=6$ for 1231 and $35 \mathrm{~S}$.

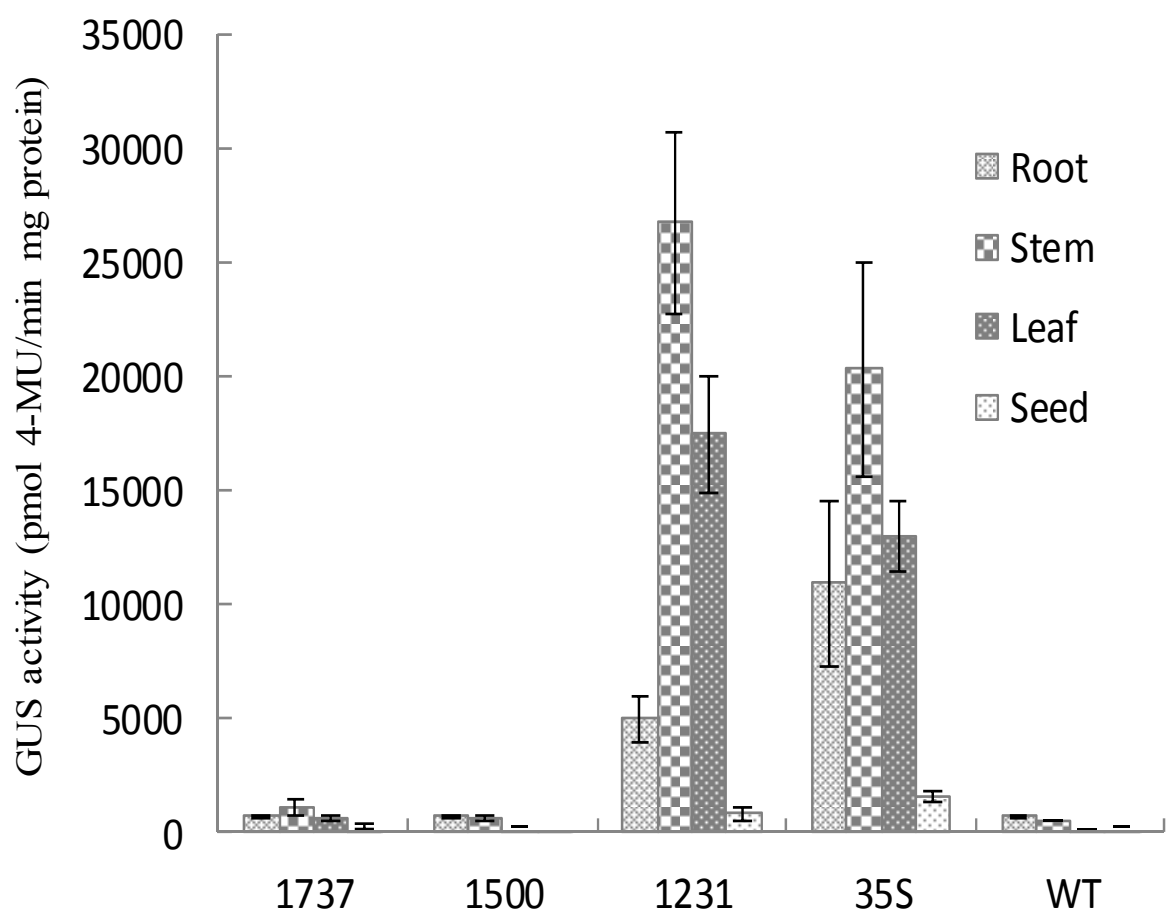

\subsection{Wip ${ }_{1231}$ Promoter Drives Low GUS Transcriptional Level}

Generally, the level of protein is consistent with the level of mRNA, but sometimes they are discordant. To confirm Wip $_{1231}$ is a strong promoter, we investigated the transcriptional levels of GUS in the transgenic tobacco plants. To our surprise, lower transcriptional levels of GUS were detected in transgenic plants containing Wipl promoters than in transgenic plants containing CaMV 35S promoter. There were higher GUS transcriptional level in Wip $_{1231}: \because G U S$ transgenic lines than in Wip $_{1737}: G U S$ and Wip $_{1500}:: G U S$ lines (Figure 7). The results of Western blot analysis showed that there were high GUS protein levels in both Wip ${ }_{1231}: \because G U S$ and $35 S:: G U S$ transgenic lines, whereas GUS protein was undetectable in Wip W737 $: G U S$, Wip W $_{1500}:: G U S$ and WT plants (Figure S1). These results indicate that the strong GUS activity in Wip $_{1231}: \because G U S$ transgenic lines can be attributed to high efficient translation of GUS protein. We speculate that there might be some translation enhancer in the 5'-UTR of GUS transcripts in Wip $_{1231}: \because G U S$ transgenic plants. 
Figure 7. Transcriptional level of GUS in transgenic tobacco leaves. Data was shown as average \pm S.E. of 6 independent transgenic lines. Letters above the columns indicate statistically significant differences at $p<0.05$ level. Relative transcript levels were calculated using the $2^{-\Delta \Delta C t}$ method [29] with Actin as a housekeeping gene.

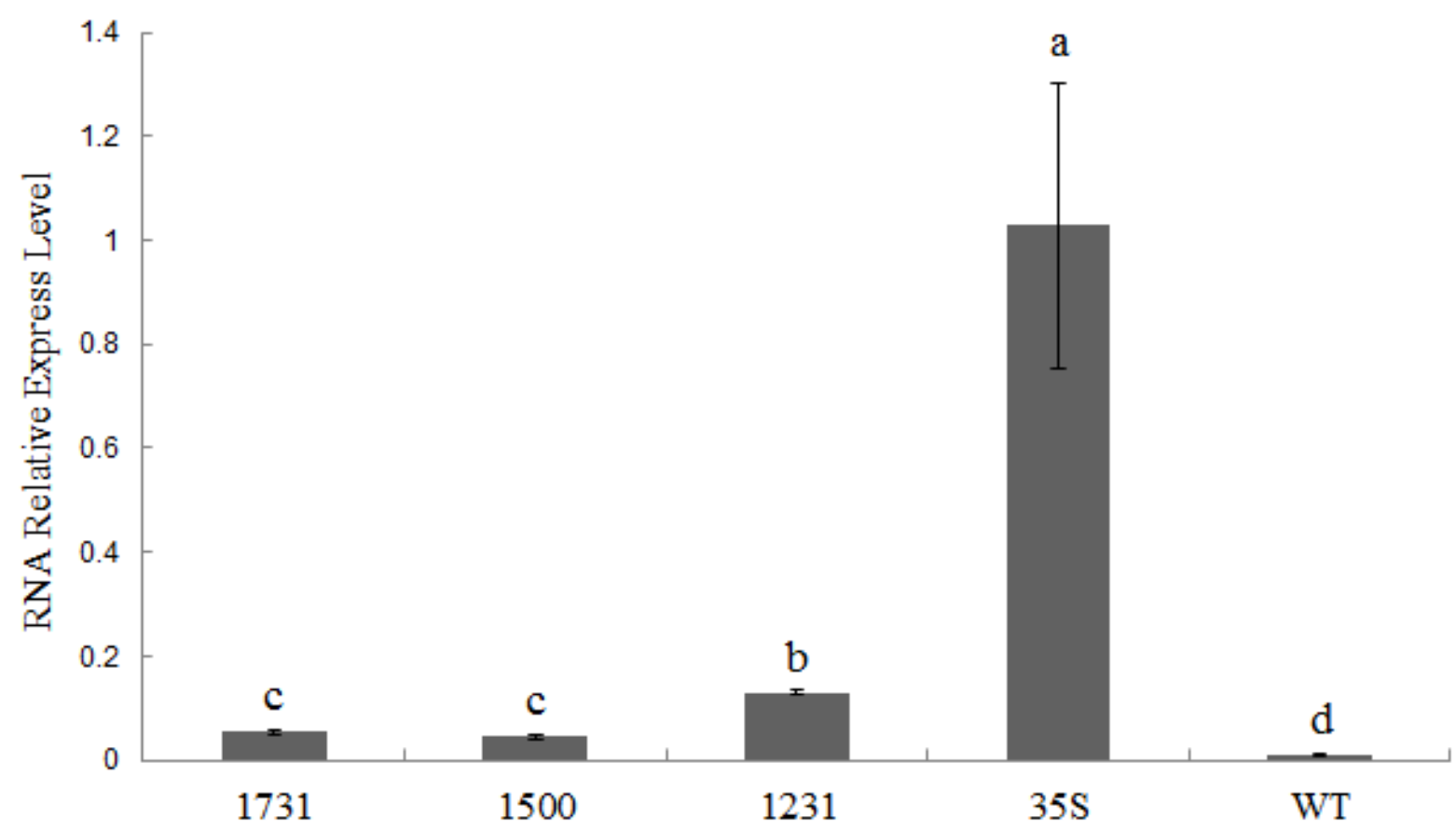

2.5. Wip1 Promoters Have Multiple GUS Transcription Start Sites in Transgenic Tobacco

To find out the exact 5'-UTRs, we further determined the accurate transcription start sites in maize and transgenic tobacco plants by the 5'-RACE method. The native transcription start site of Wip1 in maize was identified as the nucleotide $\mathrm{G}$ which is located at $61 \mathrm{bp}$ upstream of the Wipl translation

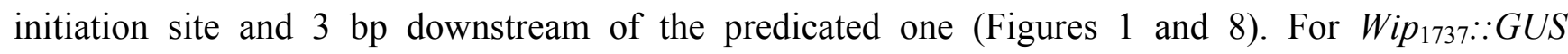
transgenic tobacco line, a strong band and one weak band were amplified, and sequencing results revealed that two transcription start sites are present (Figures 1 and 8). The latter is the same as the transcription start site of Wipl gene in maize. The former was identified as nucleotide $\mathrm{C}$ which is located at $532 \mathrm{bp}$ upstream of the ATG translation initiation site and identical to the predicated one, and this transcription start site was also identified in Wip $_{1231}: \because G U S$ transgenic tobacco line. So there is a 272 bp-length untranslated region in GUS transcripts in Wip $p_{1231}:: G U S$ lines. In the 272 bp 5'-UTR there is an ACAAAA element, several CAA trimers and several elements similar to ACAATTAC octamer (Figure S2). The elements might contribute to the high translation efficiency of GUS transcripts in Wip $_{1231}$ transgenic lines. The sequences of 5'-UTR from Wip T $_{1231}$ and Wip $_{1737}$ transgenic lines were comparatively analyzed to find that there were more uORFs in the latter (Figures S3-S5). Maybe the additional uORFs lead to the lower level of GUS transcript and GUS activity in Wip $p_{1737}$ transgenic lines. 
Figure 8. 5'-RACE analysis of the transcription start sites. M, DNA molecular marker; (1) Wipl in maize; (2) Wip $_{1231}:: G U S$ line; and (3) Wip $_{1737}:$ GUS line.

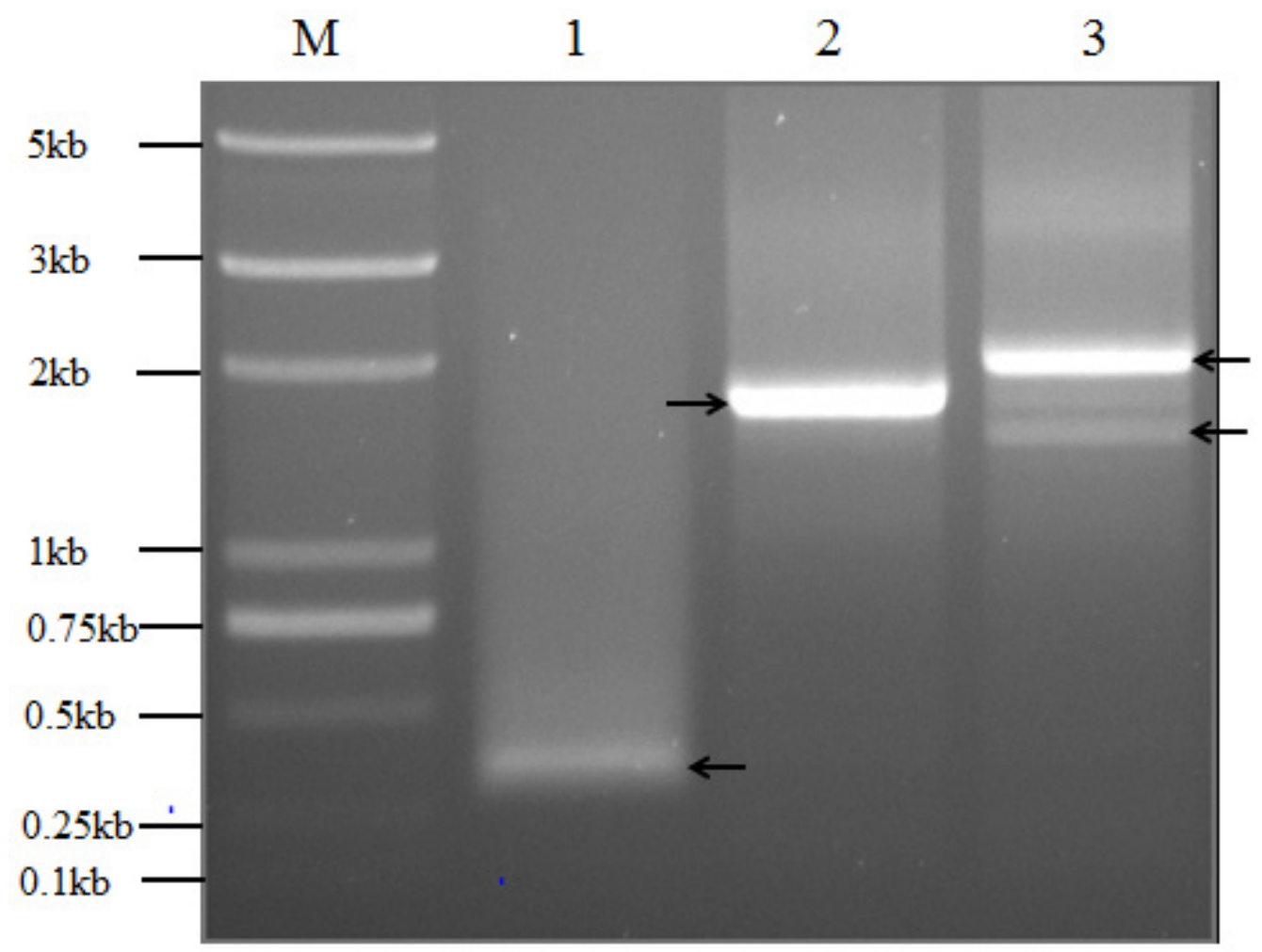

\subsection{Wip ${ }_{1231}$ Promoters Were Influenced by the Adjacent 35 S Promoter Sequence}

In this study, the transformation vectors were constructed from a derivative of the pCAMBIA1300 binary vector that includes a CaMV $35 \mathrm{~S}$ promoter controlling a hptII selectable marker gene. It has been reported that the CaMV 35S enhancer can influence the expression of a transgene within the same transformation construct [14,30,31]. To investigate whether the $35 \mathrm{~S}$ enhancer influences the truncated Wip W $_{1231}$, we constructed transformation vectors p1300-1231-NOS and p1300-35S-NOS, where the $35 \mathrm{~S}$ promoter was replaced with a NOS promoter to control the hptII selectable marker gene, and the reporter gene GUS was controlled by the Wip $p_{1231}$ promoter and $35 \mathrm{~S}$ promoter, respectively. Then they were transformed into tobacco, and transgenic tobacco plants were obtained. The GUS activity in transgenic plants transformed with p1300-1231-NOS was very low, compared to transgenic lines transformed with $\mathrm{pWip}_{1231}$. However, transgenic plants transformed with p1300-35S-NOS still had high GUS activity, which were similar to the transgenic lines transformed with p1300-221 (Figure 9). The Wip 1231 promoter was still not induced by wounding in transgenic tobacco plants which was transformed with p1300-1231-NOS (Figure 9). The above results showed that adjacent 35S promoter did enhance the expression of GUS reporter gene that was controlled by truncated Wip $_{1231}$, and the truncated Wip $_{1231}$ does not respond to wound signals in transgenic tobacco plants. 
Figure 9. GUS activity in tobacco plant leaves transformed with constructs p1300-35S-NOS or p1300-1231-NOS. The second leaves from apex of 40-day-old $\mathrm{T}_{3}$ tobacco plants grown in greenhouse were used. NW and W mean non-wounded or wounded samples using the method described in Walker-Simmons, et al. [26]. Data was shown as average \pm S.E of $n$ independent transgenic lines, $n=15$ for p1300-1231-NOS; $n=13$ for $\mathrm{p} 1300-35 \mathrm{~S}-\mathrm{NOS}$.

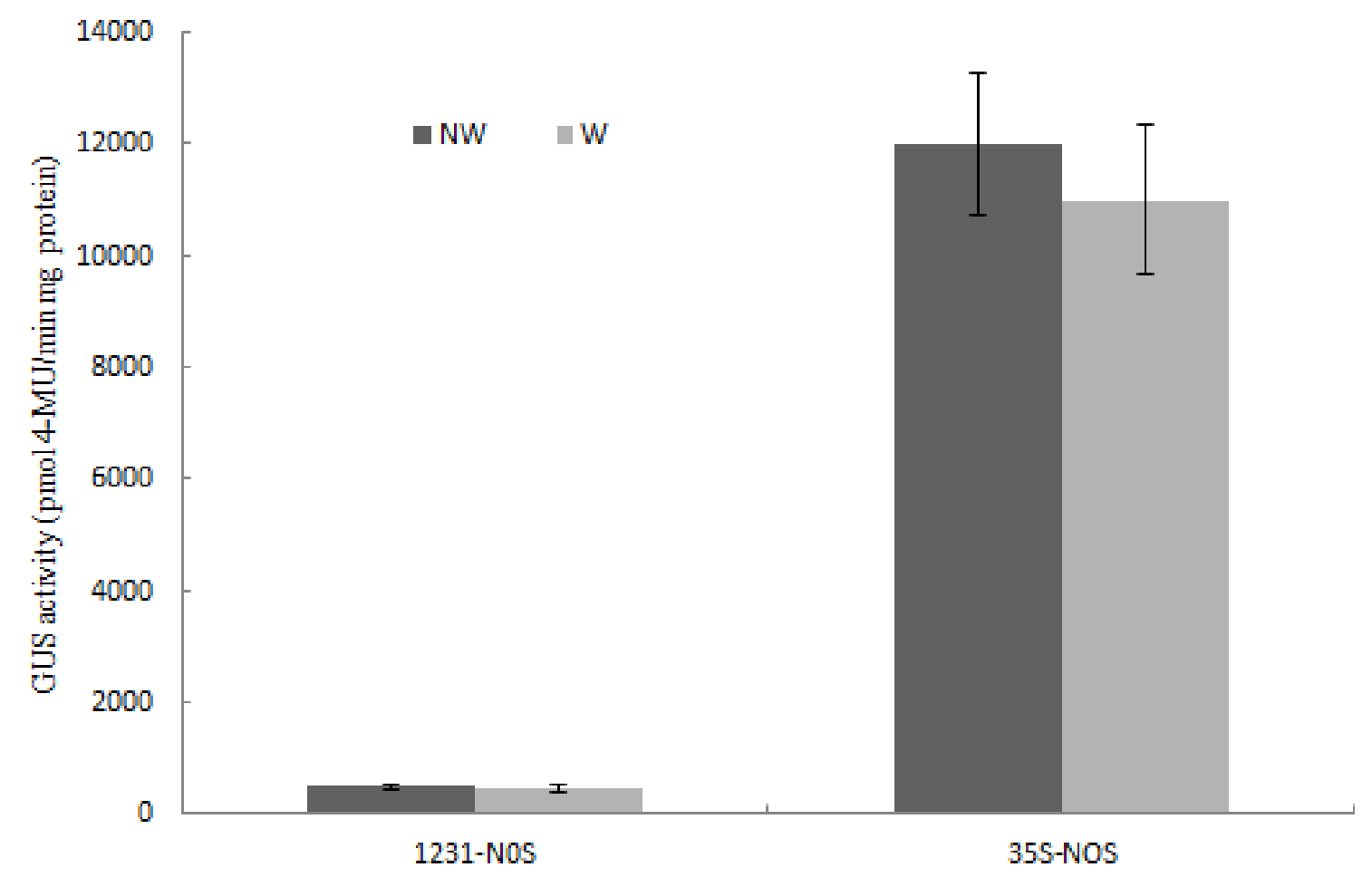

\subsection{Wip1 Promoter Is Wound Inducible in Transgenic Rice Plants}

Expression of the Wipl gene is induced through wounding in maize. However, the GUS gene, driven by Wipl promoters, was not induced by wounding in transgenic tobacco which is a dicot. This encouraged us to analyze whether Wipl promoters have the same function in monocot species. Constructs $\mathrm{pWip}_{1737}, \mathrm{pWip}_{1500}$ and $\mathrm{pWip}_{1231}$ were transformed into rice, respectively, and the transgenic rice events were confirmed by PCR analysis of the genomic DNA (data not shown). Low GUS activities were detected in transgenic rice plant leaves containing different Wipl promoters, compared with that in transgenic rice transformed with the CaMV 35S promoter. When transgenic rice leaves were wounded, significant increase of GUS activity were observed in all the transgenic lines containing different Wipl promoters, whereas the GUS activity in transgenic plants containing the $35 \mathrm{~S}$ promoter did not change (Figure 10). This indicates that the Wipl promoter is induced by wounding in rice. 
Figure 10. GUS activity in transgenic rice leaves treated with wounding. The second leaves from apex of 40-day-old rice plants grown in a greenhouse were wounded using the method described in $\mathrm{Xu}$, et al. [28]. NW and $\mathrm{W}$ mean non-wounded or wounded samples. Data was shown as average \pm S.E. of 6 independent transgenic lines. Asterisks $(* *)$ means the significant difference at $p<0.01$ level.

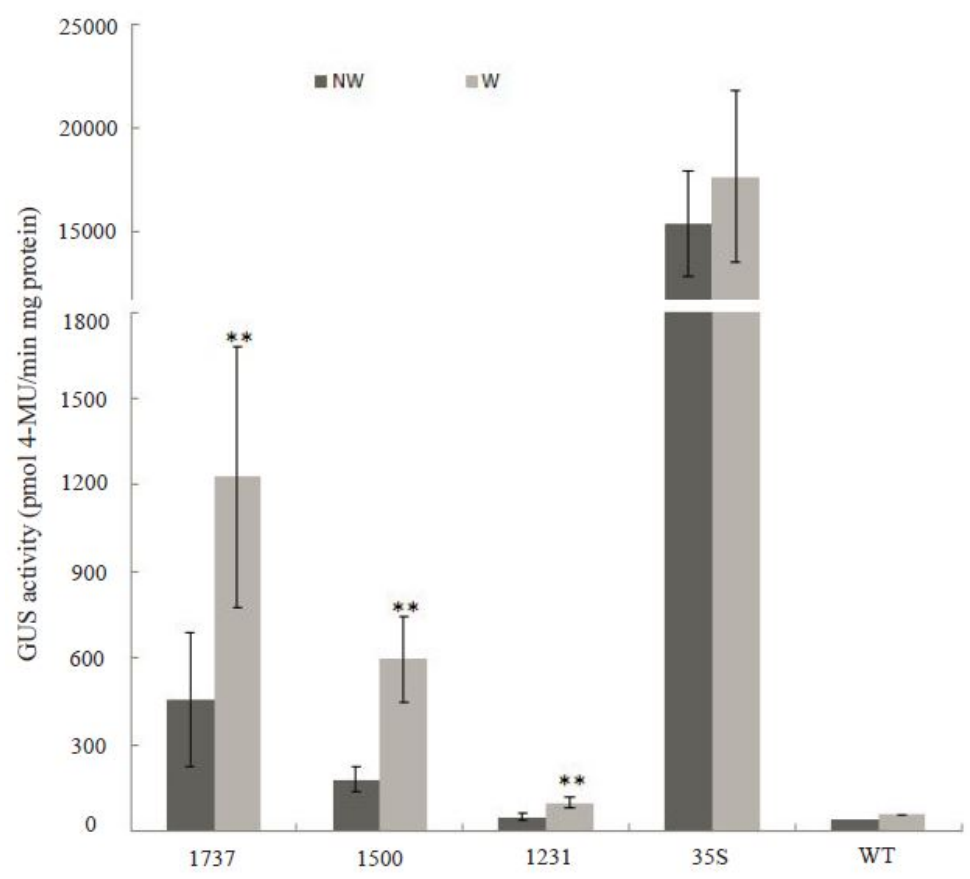

\section{Discussion}

Arabidopsis and tobacco have long been used as simple and high-efficiency transformation systems in which to analyze gene function. In addition to protein-coding genes, the promoters from rice or maize have been studied in one of these two systems [32-34]. In this study, we used both systems to study the function of maize Wipl promoter. To our surprise, expression of GUS driven by truncated maize Wipl fragments was not induced by wound in transgenic tobacco plants (Figure 5). This may be due to the fact that the maize Wipl promoter comes from a monocot, and its function may be different in monocot and dicot species. Although it has been reported that the wound-inducible PinII promoter from potato was able to drive gene expression in response to wound signals in rice [28], many plant promoters exhibit different functionality in dicots and monocots. For example, the widely used maize ubiquitin promoter conferred lower expression of a reporter gene in the tobacco (dicot) protoplasts than in maize (monocot) protoplasts [2]. Several dicot promoters also have been shown to have lower activities than monocot promoters when transformed into monocot species [35].

Few strong promoters have been identified to date, and it remains important for researchers in plant biotechnology to identify promoters that are as strong as or stronger than the CaMV $35 \mathrm{~S}$ promoter. In transgenic plants, high GUS activities were observed in transgenic lines containing truncated Wip 1 promoters even though low GUS transcriptional levels were detected. The above results indicate that truncated Wipl promoters are not strong, and the reason for the high GUS activity driven by the truncated Wipl promoters might be due to the increased translation of the GUS gene. It has been shown that the $35 S-G U S$ and $35 S-A B I 4-G U S$ lines had at least 50 fold differences in transcript level, 
however more than 300 fold difference in GUS activity was observed [36], indicating that transcriptional level is not correlated with the protein level in some cases. Many factors, i.e., promoter activity, mRNA stability, protein translation efficiency, can affect the expression level of foreign genes in transgenic plants. The high GUS activity driven by truncated Wipl promoters indicate that Wipl promoters are also useful in plant biotechnology, even though these promoters led to low transcriptional level.

Normally, a promoter shows different properties in monocot and dicot plants. It has been shown that the CaMV 35S promoter can drive high levels of transgene expression in dicot plants, whereas its activity is relatively lower in monocot plants [37]. In transgenic rice, lower activity of the Wip $p_{1231}$ promoter compared to the $35 \mathrm{~S}$ promoter was observed, and wound treatment significantly increased GUS activities in transgenic rice containing different Wipl promoters. These results are contrary to the results in transgenic tobacco, indicating that the Wipl promoter also showed different properties in monocot and dicot plants; this will limit the usage of the Wip1 promoter as a general (cross-species) promoter in transgenic crops.

5'-RACE results revealed that only one native transcription start site was present in the maize Wipl gene, and a new one was identified in both Wip $_{1737}: \because G U S$ and Wip $_{1231}: \because G U S$ transgenic tobacco lines. We analyzed the 272 bp 5'-UTR of GUS mRNA from Wip ${ }_{1231}: \because G U S$ transgenic tobacco lines to find that there is an ACAAAA hexamer, several separate CAA trimers and several elements similar to ACAATTAC octamer (Figure S2). The ACAAAA hexamer exists in many 5'-UTRs of plant genes and has been speculated to enhance translation [38]. The poly(CAA) region and ACAATTAC octamer have been confirmed to enhance translation [39-41]. The features of the sequence may contribute to the property of the 5'-UTR for high efficient translation. It has been reported that uORF plays an important role in the regulation of gene expression by different mechanisms, for example, by ribosomal stalling, reducing initiation efficiency [12]. uORF can downregulate gene expression by accelerating mRNA degradation or upregulating gene expression by reforming the 5'-UTR through the product of the uORF [42]. Six upstream ATGs (uATGs) were found in the $272 \mathrm{bp}$ UTR. Among the six uATGs, the first three are in two very short uORFs, the fourth and fifth are in the reading frame of the GUS gene and will produce GUS fusion protein, and the sixth uATG should not have the opportunity to initiate translation (Figure S3). We suggest that the two uORFs may have little possibility to influence the mORF translation. Strong GUS activity in transgenic plants transformed with pWip $_{1231}$ construct and related $\mathrm{pWip}_{1231 \mathrm{~A}}, \mathrm{pWip}_{1231 \mathrm{C}}$ and $\mathrm{pWip}_{931}$ might be due to that they all have the same 3 ' end and produce the same 5'-UTR containing two uATGs which produce GUS fusion proteins, and strong translation may initiate from the two uATGs.

14 uATGs were found in the $532 \mathrm{bp}$ UTR of GUS mRNA from Wip $p_{1737}:$ GUS transgenic tobacco lines. These uATGs form more uORFs than the six uATGs in 272 bp UTR of GUS mRNA from Wip $_{1231}: \because G U S$ transgenic lines. The fourth and fifth uATGs in the $272 \mathrm{bp}$ UTR which can produce GUS fusion protein, are in frame with a termination code in the $532 \mathrm{bp} \mathrm{UTR}$ and form a uORF.

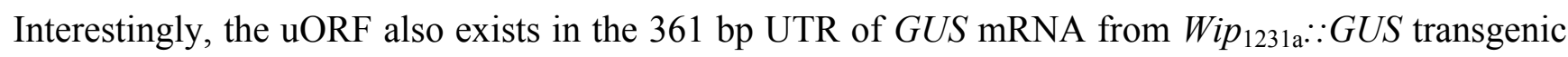
tobacco lines if the lines have the same transcription start site as Wip $_{1231}: \because G U S$ lines. We suggest that the uORF may lead to the low GUS activity of transgenic plants transformed by $\mathrm{pWip}_{1737}$ and

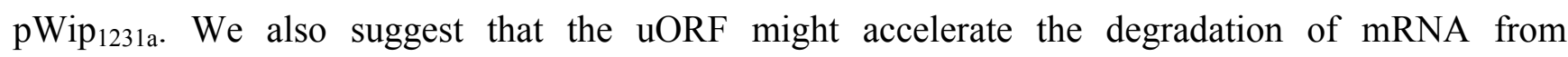
Wip $_{1731}: \because G U S$ and Wip $_{1500}: \because G U S$ transgenic tobacco lines, because the levels of mRNA in these lines 
were lower than that in Wip $_{1231}: \because G U S$ transgenic tobacco lines. We cannot exclude other factors that contribute to the attained results.

A few reports have shown that the CaMV 35S enhancer has the ability to alter the expression of nearby genes by affecting nearby promoters [14,30,31]. In the T-DNA region of transformation plasmids used for the promoter analysis, the selectable marker gene hptII was controlled with double enhanced CaMV 35S promoter. We confirmed that the 35S promoter influenced the GUS expression in Wip $_{1231}:: G U S$ transgenic plants, because low GUS activity was observed when the 35 S promoter was replaced with the NOS promoter. A problem may appear if the $35 \mathrm{~S}$ promoter exists nearby an inducible or tissue-specific promoter that drives target transgene expression, but the problem might be negligible when the adjacent promoter is a strong constitutive one. The disadvantage of the $35 \mathrm{~S}$ promoter can be overcome by using enhancer-blocking insulators to disturb the interaction between the $35 \mathrm{~S}$ promoter and adjacent promoters [43]. Every coin has two sides; maybe the property of the $35 \mathrm{~S}$ promoter can be used to develop a "strong constitutive" promoter controlling transgene expression in plants, such as the Wip 1231 and several other truncated Wipl promoters studied in the paper, although these truncated Wipl promoters drive low transcriptional level of transgene.

\section{Experimental Section}

\subsection{Isolation and Analysis of the Maize Wip1 Promoter}

Maize genomic DNA was isolated from leaves according to a previously described method [44]. A 1737 bp fragment designated as the full-length promoter sequence was amplified using the primers F1737 (5'-AACTGCAGGGCTCCGTTCTACTTGACT-3') and R1737 (5'-CGGGATCCGGTCTCGGACGAGCTGTTCTT-3'). The underlined letters indicate Pst $\mathrm{I}$ and BamHI restriction sites. Regulatory motifs were identified using PlantCARE [23] and PLACE [24], the transcription start sites were predicated on the website: http://www.fruitfly.org/seq_tools/promoter.html [25].

\subsection{Plasmid Construction}

The plasmid pBI221 was digested with HindIII and EcoRI. The CaMV 35S promoter-GUS-NOS fragment was purified and ligated into plasmid pCAMBIA1300 that had been digested with the same enzymes to construct the plasmid pCAMBIA1300-221. The amplified $1737 \mathrm{bp}$ full-length promoter sequence was digested with restriction enzymes Pst I and Bam $\mathrm{HI}$ and inserted upstream of the GUS gene in plasmid pCAMBIA1300-221, replacing the CaMV 35S promoter to construct a new plasmid, pWip 1737 (Figure S6). The full-length Wipl promoter was replaced with other truncated Wipl promoters to construct the other vectors. The details for the primers used to amplify the truncated promoters are shown in Figure 1 and Tables 1 and 2.

To construct vectors where $35 \mathrm{~S}$ promoter was replaced with NOS promoter to control hptII selectable gene, NOS promoter was amplified using Gateway binary vector pGWB454 (AB294466.1) as template with primer F-NOS (5'-CCAACATGGTGGCATCATGAGCGGAGAATTAAG-3') and primer R-NOS (5'-CTCGAGAGATCCGGTGCAGATTATTTG-3'). The underlined letters indicate $B s t$ XI and XhoI restriction sites, respectively. The vector $\mathrm{pWip}_{1231}$ was digested with BstXI and XhoI 
to produce three fragments, a $10 \mathrm{~kb}$ fragments containing vector bone, a $1.1 \mathrm{~kb}$ fragment containing hptII gene and a $0.8 \mathrm{~kb}$ fragment containing 35S promoter. The 10 and $1.1 \mathrm{~kb}$ fragments were gel purified separately and the $0.8 \mathrm{~kb}$ one was discarded. The $10 \mathrm{~kb}$ purified fragment ligated with the amplified NOS promoter fragment was digested by the same endonucleases to form the medium vector that was digested by XhoI. Then the purified product ligated with the $1.1 \mathrm{~kb}$ purified fragment in correct orientation to form the vector p1300-1231-NOS. The new control vector p1300-35S-NOS derived from pCAMBIA1300-221 was constructed similarly. The restriction endonuclease sites were in marked in detail in supplementary Figure S1.

\subsection{Plant Transformation}

For the tobacco plant transformations, the plant expression plasmids were transferred into competent Agrobacterium tumefaciens (strain LBA4404) cells by freeze-thaw treatment. The transformed Agrobacterium were selected on YEB-agar plates containing $100 \mathrm{mg} / \mathrm{L}$ kanamycin and $100 \mathrm{mg} / \mathrm{L}$ streptomycin. Recombinant Agrobacterium were infiltrated into the young tobacco (Nicotiana tobacum) leaves according to the described method [45]. For the Arabidopsis transformations, vector constructs were transformed into Agrobacterium tumefaciens strain GV3101. Arabidopsis ecotype Columbia Col-0 was transformed using the floral dip method [46]. The obtained tobacco and Arabidopsis $\mathrm{T}_{0}$ seeds were selected on MS medium plates containing $30 \mathrm{mg} / \mathrm{L}$ Hygromycin B to eliminate the non-transgenic plants.

For the rice transformation, vector constructs were transformed into Agrobacterium tumefaciens strain EHA105. Three-week-old calli derived from mature seed (Rryza sativa L. cv. Kita-ake) were used for the transformation. The transformation was performed according to the described method [47].

\subsection{Wounding of Transgenic Plant Leaves}

The second leaves from apex of 40-day-old $\mathrm{T}_{3}$ tobacco plants grown in greenhouse were wounded using three different kinds of methods. The first wound treatment was performed according to Walker-Simmons, et al. [26] wherein the leaves were crushed across the midvein by a hemostat, with a second wounding $20 \mathrm{~h}$ later, and the leave samples were harvested $24 \mathrm{~h}$ after the first wounding. The second wound treatment was performed according to An, et al. [27] wherein the leaves were cut into about $1 \mathrm{~cm}^{2}$ sections and the leaf slices were put in Murashige and Skoog (MS) liquid medium containing $3 \%$ sucrose ( $\mathrm{pH}$ 5.8). The leaf slices were wounded by making several small holes in each section with forceps, and then were placed in tissue culture incubator at $28{ }^{\circ} \mathrm{C}$ for $24 \mathrm{~h}$ under light (3000 Lux), then the samples were harvested for the experiment. The third wound treatment was performed according to the method described by Xu, et al. [28] wherein the leaves were cut three times perpendicularly to the midvein by a scissor along both edges of the leaf blade without damaging the midvein. The first leaf under the wounding one was cut off before wounding as unwounded sample, frozen in liquid nitrogen and stored at $-80{ }^{\circ} \mathrm{C}$ before extracting crude protein.

For the wounding of rice leaves, the second leaves from apex of 40-day-old $\mathrm{T}_{2}$ rice plants grown in greenhouse were wound according to the method described by $\mathrm{Xu}$, et al. [28] wherein the leaves were cut at intervals of $1 \mathrm{~cm}$ perpendicularly to veins by a scissor along both edges of the leaf blade without damaging the midvein, and the leave samples were harvested $24 \mathrm{~h}$ after wounding. The first leaf under 
the wounding one was cut off before wounding as unwounded sample, frozen in liquid nitrogen and stored at $-80^{\circ} \mathrm{C}$ before extracting crude protein.

\subsection{Analysis of RNA Level by $q R T-P C R$}

The second leaf from the apex of 40 -day-old $\mathrm{T}_{3}$ transgenic tobacco was sampled. Total RNA was extracted using EasyPure ${ }^{\mathrm{TM}}$ Plant RNA Kit (TransGen, Beijing, China). The RNA was reverse transcribed to cDNA using TransScript ${ }^{\circledR}$ II First-Strand cDNA Synthesis SuperMix Kit (TransGen, Beijing, China), and qRT-PCR was performed using the TransStart ${ }^{\circledR}$ Green qPCR SuperMix Kit from Beijing TransGen Biotech Co. Ltd. (Beijing, China). The primers used for qRT-PCR were designed according to the sequences of the GUS gene from vector pBI221 (AF502128.1) and tobacco Actin gene (U60495.1). The sense primer for GUS gene is S-GUS: 5'-CCAACTCCTACCGTACCTC-3', and the antisense primer is A-GUS: 5'-TCGAAACCAATGCCTAAA-3'. The sense primer for Actin gene is S-ACTIN: 5'-AAGGGATGCGAGGATGGA-3', and the antisense primer is A-ACTIN: 5'-CAAGGAAATCACCGCTTTGG-3'. The instrument of ABI 7300 was used. The reaction volume is $20 \mu \mathrm{L}$. The amplification program was: $95{ }^{\circ} \mathrm{C} 2 \mathrm{~min}$ for pre-denature, then 40 cycles of $95{ }^{\circ} \mathrm{C} 10 \mathrm{~s}$ for denature, $55{ }^{\circ} \mathrm{C} 30 \mathrm{~s}$ for annealing, $72{ }^{\circ} \mathrm{C} 31 \mathrm{~s}$ for elongation were followed. The fluorescence data was collected at the end of elongation and analyzed by the $2^{-\Delta \Delta C t}$ method [29].

\subsection{Analysis of the Transcription Start Sites by 5' Rapid Amplification of cDNA Ends (5'-RACE)}

According to the sequences of maize Wipl gene (X71396.1) and GUS gene from vector pBI221 (AF502128.1), two specific primers, wip1-R: 5'-CAAAAAGGACTGCGACCCCGTCTG-3' and GUS-R: 5'-GTTCTGCGACGCTCACACCGATACC-3', were designed. wip1-R was used to amplify the $5^{\prime}$ end of Wipl mRNA in maize. GUS-R was used to amplify the $5^{\prime}$ end of GUS mRNA in transgenic tobacco. Total RNA was extracted from leaves of 10-day-old maize inbred line Z31 and 30-day-old transgenic tobacco plants using EasyPure ${ }^{\mathrm{TM}}$ Plant RNA Kit (TransGen, Beijing, China). The generation of RACE-ready cDNA and rapid amplification of cDNA end were performed strictly according to the user manual of SMARTer ${ }^{\mathrm{TM}}$ RACE cDNA Amplification Kit (Clontech, Mountain View, CA, USA).

\subsection{GUS Activity Assay and Histochemical Staining}

$\mathrm{T}_{2}$ transgenic tobacco seeds were germinated on MS medium plates with $30 \mathrm{mg} / \mathrm{L}$ Hygromycin $\mathrm{B}$ to eliminate the non-transgenic plants. The surviving 14-day-old seedlings were immersed in GUS staining solution [48] and incubated overnight at $37{ }^{\circ} \mathrm{C}$. Then, the samples were de-pigmented with $70 \%$ ethanol at $37^{\circ} \mathrm{C}$ until the chlorophyll had completely disappeared.

For quantitative analysis, young leaves of 40-day-old $\mathrm{T}_{3}$ tobacco seedlings and 20-day-old $\mathrm{T}_{3}$ Arabidopsis seedlings were homogenized in $500 \mu \mathrm{L}$ extraction buffer (50 mM sodium phosphate buffer, $\mathrm{pH}$ 7.0, $10 \mathrm{mM}$ EDTA, 0.1\% Triton X-100, $10 \mathrm{mM} \beta$-mercaptoethanol) and clarified by centrifugation at $13,000 \mathrm{rpm}$ for $10 \mathrm{~min}$ at $4{ }^{\circ} \mathrm{C} .10 \mu \mathrm{L}$ supernatant was used to assay the GUS activity in $100 \mu \mathrm{L}$ extraction buffer containing $2 \mathrm{mM}$ 4-methylumbelliferyl- $\beta$-D-glucuronide. Fluorescence was measured using Skanlt 2.4.3 RE for Varioskan Flash (Thermo, Waltham, MA, USA). Protein 
concentration was determined using the Model 680 spectrophotometer (Bio-Rad, Philadelphia, PA, USA) using the Coomassie Brilliant Blue method [49].

\section{Conclusions}

We used standard methods to study the function of the maize Wipl promoter and found that several truncated Wipl promoters led to high GUS activity in transgenic plants, even though the GUS transcriptional level was relatively low. The high GUS activity may be ascribed to high translation efficiency. The activity of the truncated Wipl promoter fragments were influenced by the adjacent $35 \mathrm{~S}$ promoter, however they may also be used as strong constitutive promoters to drive transgenes in plant biotechnology when a $35 \mathrm{~S}$ promoter exists nearby. This may be a way to develop new "strong constitutive" promoters.

\section{Acknowledgments}

We thank Jianmin Wan and Xin Zhang from Institute of Crop Sciences, Chinese Academy of Agricultural Sciences (Beijing, China) for the help on the rice transformation.

\section{Conflicts of Interest}

The authors declare no conflict of interest.

\section{References}

1. Fang, R.X.; Nagy, F.; Sivasubramaniam, S.; Chua, N.H. Multiple cis regulatory elements for maximal expression of the cauliflower mosaic virus $35 \mathrm{~S}$ promoter in transgenic plants. Plant Cell 1989, 1, 141-150.

2. Christensen, A.H.; Sharrock, R.A.; Quail, P.H. Maize polyubiquitin genes: Structure, thermal perturbation of expression and transcript splicing, and promoter activity following transfer to protoplasts by electroporation. Plant Mol. Biol. 1992, 18, 675-689.

3. Zhang, W.; McElroy, D.; Wu, R. Analysis of rice Act1 5' region activity in transgenic rice plants. Plant Cell 1991, 3, 1155-1165.

4. Cazzonelli, C.I.; McCallum, E.J.; Lee, R.; Botella, J.R. Characterization of a strong, constitutive mung bean (Vigna radiata L.) promoter with a complex mode of regulation in planta. Transgenic Res. 2005, 14, 941-967.

5. Stavolone, L.; Kononova, M.; Pauli, S.; Ragozzino, A.; de Haan, P.; Milligan, S.; Lawton, K.; Hohn, T. Cestrum yellow leaf curling virus (CmYLCV) promoter: A new strong constitutive promoter for heterologous gene expression in a wide variety of crops. Plant Mol. Biol. 2003, 53, 663-673.

6. Xie, Y.; Liu, Y.; Meng, M.; Chen, L.; Zhu, Z. Isolation and identification of a super strong plant promoter from cotton leaf curl Multan virus. Plant Mol. Biol. 2003, 53, 1-14.

7. Dynan, W.S. Modularity in promoters and enhancers. Cell 1989, 58, 1-4. 
8. Sunilkumar, G.; Mohr, L.; Lopata-Finch, E.; Emani, C.; Rathore, K.S. Developmental and tissue-specific expression of CaMV 35S promoter in cotton as revealed by GFP. Plant Mol. Biol. 2002, 50, 463-474.

9. Boyko, A.; Molinier, J.; Chatter, W.; Laroche, A.; Kovalchuk, I. Acute but not chronic exposure to abiotic stress results in transient reduction of expression levels of the transgene driven by the 35S promoter. New Biotechnol. 2010, 27, 70-77.

10. Yin, T.; Wu, H.; Zhang, S.; Lu, H.; Zhang, L.; Xu, Y.; Chen, D.; Liu, J. Two negative cis-regulatory regions involved in fruit-specific promoter activity from watermelon (Citrullus vulgaris $\mathrm{S}$.). J. Exp. Bot. 2009, 60, 169-185.

11. Wilkie, G.S.; Dickson, K.S.; Gray, N.K. Regulation of mRNA translation by 5'- and 3'-UTR-binding factors. Trends Biochem. Sci. 2003, 28, 182-188.

12. Tran, M.K.; Schultz, C.J.; Baumann, U. Conserved upstream open reading frames in higher plants. BMC Genomics 2008, 9, 361.

13. $\mathrm{Wu}$, J.; Miller, B.L. Aspergillus asexual reproduction and sexual reproduction are differentially affected by transcriptional and translational mechanisms regulating stunted gene expression. Mol. Cell Biol. 1997, 17, 6191-6201.

14. Zheng, X.; Deng, W.; Luo, K.; Duan, H.; Chen, Y.; McAvoy, R.; Song, S.; Pei, Y.; Li, Y. The cauliflower mosaic virus (CaMV) $35 \mathrm{~S}$ promoter sequence alters the level and patterns of activity of adjacent tissue-and organ-specific gene promoters. Plant Cell Rep. 2007, 26, 1195-1203.

15. Yang, Y.; Singer, S.D.; Liu, Z. Evaluation and comparison of the insulation efficiency of three enhancer-blocking insulators in plants. Plant Cell Tissue Organ Cult. 2011, 105, 405-414.

16. Qi, R.F.; Song, Z.W.; Chi, C.W. Structural features and molecular evolution of Bowman-Birk protease inhibitors and their potential application. Acta Biochim. Biophys. Sin. 2005, 37, 283-292.

17. Shitan, N.; Horiuchi, K.; Sato, F.; Yazaki, K. Bowman-birk proteinase inhibitor confers heavy metal and multiple drug tolerance in yeast. Plant Cell Physiol. 2007, 48, 193-197.

18. Qu, L.J.; Chen, J.; Liu, M.; Pan, N.; Okamoto, H.; Lin, Z.; Li, C.; Li, D.; Wang, J.; Zhu, G.; et al. Molecular cloning and functional analysis of a novel type of Bowman-Birk inhibitor gene family in rice. Plant Physiol. 2003, 133, 560-570.

19. Eckelkamp, C.; Ehmann, B.; Schopfer, P. Wound-induced systemic accumulation of a transcript coding for a Bowman-Birk trypsin inhibitor-related protein in maize (Zea mays L.) seedlings. FEBS Lett. 1993, 323, 73-76.

20. Rohrmeier, T.; Lehle, L. WIP1, a wound-inducible gene from maize with homology to Bowman-Birk proteinase inhibitors. Plant Mol. Biol. 1993, 22, 783-792.

21. Tiffin, P.; Gaut, B.S. Molecular evolution of the wound-induced serine protease inhibitor wip1 in Zea and related genera. Mol. Biol. Evol. 2001, 18, 2092-2101.

22. Maize Genetics and Genomics Database. Available online: http://www.maizegdb.org/ (accessed on 20 May 2010).

23. Lescot, M.; Déhais, P.; Thijs, G.; Marchal, K.; Moreau, Y.; van de Peer, Y.; Rouzé, P.; Rombauts, S. PlantCARE, a database of plant cis-acting regulatory elements and a portal to tools for in silico analysis of promoter sequences. Nucleic Acids Res. 2002, 30, 325-327.

24. Higo, K.; Ugawa, Y.; Iwamoto, M.; Korenaga, T. Plant cis-acting regulatory DNA elements (PLACE) database: 1999. Nucleic Acids Res. 1999, 27, 297-300. 
25. Reese, M.G. Neural Network Promoter Prediction. Available online: http://www.fruitfly.org/ seq_tools/promoter.html (accessed on 27 October 2010).

26. Walker-Simmons, M.; Holländer-Czytko, H.; Andersen, J.K.; Ryan, C.A. Wound signals in plants: A systemic plant wound signal alters plasma membrane integrity. Proc. Natl. Acad. Sci. USA 1984, 81, 3737-3741.

27. An, G.; Mitra, A.; Choi, H.K.; Costa, M.A.; An, K.; Thornburg, R.W.; Ryan, C.A. Functional analysis of the 3 'control region of the potato wound-inducible proteinase inhibitor II gene. Plant Cell 1989, 1, 115-122.

28. Xu, D.; McElroy, D.; Thornburg, R.W.; Wu, R. Systemic induction of a potato pin2 promoter by wounding, methyl iasmonate, and abscisic acid in transgenic rice plants. Plant Mol. Biol. 1993, 22, 573-588.

29. Livak, K.J.; Schmittgen, T.D. Analysis of relative gene expression data using real-time quantitative PCR and the $2^{-\Delta \Delta \mathrm{Ct}}$ method. Methods 2001, 25, 402-408.

30. Yoo, S.Y.; Bomblies, K.; Yoo, S.K.; Yang, J.W.; Choi, M.S.; Lee, J.S.; Weigel, D.; Ahn, J.H. The 35S promoter used in a selectable marker gene of a plant transformation vector affects the expression of the transgene. Planta 2005, 221, 523-530.

31. Singer, S.D.; Cox, K.D.; Liu, Z. Both the constitutive cauliflower mosaic virus $35 \mathrm{~S}$ and tissue-specific AGAMOUS enhancers activate transcription autonomously in Arabidopsis thaliana. Plant Mol. Biol. 2010, 74, 293-305.

32. Chen, X.; Wang, Z.; Gu, R.; Fu, J.; Wang, J.; Zhang, Y.; Wang, M.; Zhang, J.; Jia, J.; Wang, G. Isolation of the maize $\mathrm{Zpul}$ gene promoter and its functional analysis in transgenic tobacco plants. Plant Cell Rep. 2007, 26, 1555-1565.

33. Lü, S.; Gu, H.; Yuan, X.; Wang, X.; Wu, A.M.; Qu, L.; Liu, J.Y. The GUS reporter-aided analysis of the promoter activities of a rice metallothionein gene reveals different regulatory regions responsible for tissue-specific and inducible expression in transgenic Arabidopsis. Transgenic Res. 2007, 16, 177-191.

34. Ren, Y.; Zhao, J. Functional analysis of the rice metallothionein gene OsMT2b promoter in transgenic Arabidopsis plants and rice germinated embryos. Plant Sci. 2009, 176, 528-538.

35. Wilmink, A.; van de Ven, B.C.; Dons, J.J. Activity of constitutive promoters in various species from the Liliaceae. Plant Mol. Biol. 1995, 28, 949-955.

36. Finkelstein, R.; Lynch, T.; Reeves, W.; Petitfils, M.; Mostachetti, M. Accumulation of the transcription factor ABA-insensitive (ABI)4 is tightly regulated post-transcriptionally. J. Exp. Bot. 2011, 62, 3971-3979.

37. Park, S.H.; Yi, N.; Kim, Y.S.; Jeong, M.H.; Bang, S.W.; Choi, Y.D.; Kim, J.K. Analysis of five novel putative constitutive gene promoters in transgenic rice plants. J. Exp. Bot. 2010, 61, 2459-2467.

38. Caspar, T.; Quail, P.H. Promoter and leader regions involved in the expression of the Arabidopsis ferredoxin A gene. Plant J. 1993, 3, 161-174.

39. Gallie, D.R.; Sleat, D.E.; Watts, J.W.; Turner, P.C.; Wilson, T.M.A. Mutational analysis of the tobacco mosaic virus 5'-leader for altered ability to enhance translation. Nucleic Acids Res. 1988, 16, 883-893.

40. Gallie, D.R.; Walbot, V. Identification of the motifs within the tobacco mosaic virus 5'-leader responsible for enhancing translation. Nucleic Acids Res. 1992, 20, 4631-4638. 
41. De Amicis, F.; Patti, T.; Marchetti, S. Improvement of the pBI121 plant expression vector by leader replacement with a sequence combining a poly (CAA) and a CT motif. Transgenic Res. 2007, 16, 731-738.

42. Morris, D.R.; Geballe, A.P. Upstream open reading frames as regulators of mRNA translation. Mol. Cell. Biol. 2000, 20, 8635-8642.

43. Singer, S.D.; Cox, K.D.; Liu, Z. Enhancer-promoter interference and its prevention in transgenic plants. Plant Cell Rep. 2011, 30, 723-731.

44. Aljanabi, S.M.; Martinez, I. Universal and rapid salt-extraction of high quality genomic DNA for PCR-based techniques. Nucleic Acids Res. 1997, 25, 4692-4693.

45. Horsch, R.; Fry, J.; Hoffman, N.; Eichholz, D.; Rogers, S.; Fraley, R. A simple and general method for transferring genes into plants. Science 1985, 227, 1229-1231.

46. Clough, S.J.; Bent, A.F. Floral dip: A simplified method for Agrobacterium-mediated transformation of Arabidopsis thaliana. Plant J. 1998, 16, 735-743.

47. Goto, F.; Yoshihara, T.; Shigemoto, N.; Toki, S.; Takaiwa, F. Iron fortification of rice seed by the soybean ferritin gene. Nat. Biotechnol. 1999, 17, 282-286.

48. Jefferson, R.A.; Kavanagh, T.A.; Bevan, M.W. GUS fusions: Beta-glucuronidase as a sensitive and versatile gene fusion marker in higher plants. EMBO J. 1987, 6, 3901-3907.

49. Bradford, M.M. A rapid and sensitive method for the quantitation of microgram quantities of protein utilizing the principle of protein-dye binding. Anal. Biochem. 1976, 72, 248-254.

(C) 2013 by the authors; licensee MDPI, Basel, Switzerland. This article is an open access article distributed under the terms and conditions of the Creative Commons Attribution license (http://creativecommons.org/licenses/by/3.0/). 